\section{A. ARS BILDUMA ISSN 1989-9262 UPV/EHU Press} ARSBILDUMA (CC BY-NC-ND 4.0)

https://doi.org/10.1387/ars-bilduma.21927 BIBLID [(2021), 11; 49-67]

Recibido: 14/04/2020 Aceptado: 17/06/2020

\section{LAUREN ETXEPARE IGIÑIZ}

Universidad del País Vasco (UPV/EHU)

Departamento de Arquitectura

Escuela Técnica Superior de Arquitectura,

Plaza Oñati, 2

20018 Donostia-San Sebastián (Guipúzcoa)

lauren.etxepare@ehu.eus

https://orcid.org/0000-0002-9849-1244

\title{
OBRAS TUNECINAS DE JOSEPH HIRIART, MAESTRO DEL ART-DÉCO (1927-1936)
}

\author{
OEUVRES TUNISIENNES DE JOSEPH HIRIART, MAÎTRE DE L'ART-DÉCO (1927- \\ 1936)
}

TUNISIAN WORKS OF JOSEPH HIRIART, MASTER OF ART-DÉCO (1927-1936)

\section{RESUMEN}

Joseph Hiriart fue uno de los principales arquitectos de la Exposition des Arts décoratifs industriels et modernes celebrada en Paris (1925). Desde su estudio de París, junto con sus asociados Georges Beau y Georges Tribout, proyectó un conjunto de brillantes obras, entre las que destacan las realizadas en el País Vasco francés. En 1927, en vista de la recesión económica y tras asociarse con Jean-Marcel Seignouret, Hiriart abrió un estudio en la ciudad de Túnez. Durante diez años, llevaron a cabo una serie de proyectos residenciales y dotacionales, que, aunque memorables, han permanecido en el olvido. Es hora de conocerlos.

\section{PALABRAS CLAVE}

Joseph Hiriart; Jean-Marcel Seignouret; Túnez; Arquitectura Art-Déco.

\section{ABSTRACT}

Joseph Hiriart was one of the principal architects of the Exposition des Arts décoratifs industriels et modernes, in Paris (1925). From his studio in Paris, together with his associates Georges Beau and Georges Tribout, he designed a set of brilliant works, among which the ones carried out in the Basque Country. In 1927, in view of the economic recession and after partnering with Jean-Marcel Seignouret, Hiriart opened a studio in Tunis. For ten years, they carried out a series of residential and educational projects that, even though they are memorable, have remained in oblivion. It is time to know about them.

\section{KEYWORDS}

Joseph Hiriart; Jean-Marcel Seignouret; Tunis; Art-Déco Architecture.

\section{RÉSUMÉ}

Joseph Hiriart a été l'un des principaux architectes de l' Exposition des Arts décoratifs industriels et modernes, tenue à Paris (1925). Depuis son agence de Paris, avec ses partenaires Georges Beau et Georges Tribout, il a projeté un ensemble d'oeuvres brillantes, parmi celles réalisées au Pays Basque. En 1927, dans le contexte de la récession économique et après sêtre associé à Jean-Marcel Seignouret, il a ouverte une agence à Tunis. Pendant dix ans ils ont réalisé une série de projets résidentiels et dotationnels, qui, bien que memorables, sont restés dans l'oubli. Il est temps de les connaître.

\section{MOTS-CLÉS}

Joseph Hiriart; Jean-Marcel Seignouret; Tunis; Architecture Art-Déco. 


\section{INTRODUCCIÓN}

Tras finalizar la Primera Guerra Mundial (1914-18) se abría en Francia un periodo de prosperidad y optimismo, favorecido por la recuperación económica, especialmente para las clases pudientes. La aviación y la automoción experimentarían un fuerte avance, de la mano del cual vino el desarrollo definitivo del turismo y la apertura de todo tipo de lugares dedicado al ocio, como casinos, hoteles y balnearios. Fue en en aquel ambiente en el que la Société des artistes décorateurs, fundada a comienzos de siglo tras la Exposición Universal de París de 1900, recuperaría su actividad anterior a la Gran Guerra. Tras un periodo de consolidación y crecimiento jalonado por una serie de exposiciones, la sociedad organizó, en 1925, la Exposition internationale des Arts décoratifs et industriels modernes, la gran exposición de la mano de la cual llegó la eclosión de las artes decorativas y la puesta de largo de un nuevo estilo: el Art-Déco ${ }^{1}$.

El hecho de que se alimentara de distintas fuentes estéticas le daba al nuevo estilo una vocación internacional. Sus motivos geométricos, figuras estilizadas y la profusión decorativa que le caracterizan, se propagarían de manera asombrosa, manifestándose en todo tipo de edificios levantados por doquier: los rascacielos de Manhattan, las mansiones de Miami y La Habana, las iglesias de Rio de Janeiro o Sao Paulo; las torres de Shanghai, los monumentos de Belgrado o Novi Sadeko; Hanoi, Phnom Penh o Saigón. Tuvo, así mismo, una gran expansión en las ciudades coloniales francesas, como Argel, Casablanca y Túnez. Todas ellas se convirtieron en el campo de ensayo y expansión del nuevo lenguaje. El Art Déco fue, al fin y al cabo, el último intento por parte de Francia de exportar un estilo propio mediante el cual afianzar y extender su influencia en el mundo ${ }^{2}$.

No fue el único estilo de la época. Tuvo que convivir con otros, ya fuera pacífica o conflictivamente; una de sus principales características, en lo que a la arquitectura se refiere, consiste, precisamente, en la dialéctica mantenida con el Movimiento Moderno.

1 Ha sido indispensable, para la escritura de este artículo, el libro de LANNES V.: Joseph Hiriart. Architecte de la lumière, en el que se da cuenta de buena parte de los trabajos de Hiriart; ahora bien, en lo relativo a sus obras tunecinas, su referencia se limita a mencionar sucintamente algunas de ellas (pp. 124-129). Este artículo pretende complementar al libro en lo que a la etapa tunecina se refiere. Sirva esta nota como agrader

2 BRÉON E., RIVOIRARD P. (Dir.s): 1925 Quand l’Art déco séduit le monde. Paris, Cité de l'architecture et du patrimoine, 2013
La historiografía de la arquitectura del siglo veinte ha venido definiendo al Art-Déco en función de sus diferencias con respecto a aquel, como un estilo que difícilmente puede considerarse moderno. Se trataba, al fin y al cabo, de un estilo decorativo, y hacía ya tiempo que la arquitectura moderna había establecido la absoluta autonomía de la obra artística, disociando totalmente la arquitectura de la decoración. En el terreno político, por otra parte, el Art-Déco no era lo suficientemente utópico o revolucionario; era casi un estilo frívolo, que rehuía de cuestiones sociales. Si el Movimiento Modeno perseguía la industrialización y la vivienda social, el Art-Déco no tenía otro objetivo que la belleza; una belleza abstracta a lo sumo, pero sin un objetivo trascendental.

Los arquitectos de entreguerras tuvieron que optar entre los dos lenguajes: los lujosos trabajos de renombre para las élites de la época, realizados bajo un concepto integral de la obra de arte, o la arquitectura estandarizada, económica e industrializada. Dos visiones contrapuestas que se manifestaron ya en la propia Exposition internationale des Arts décoratifs et industriels modernes de 1925: por un lado, el bando de los modernos, con August Perret, Le Corbusier, Robert Mallet-Stevens, Konstantin Melnikov y su pabellón constructivista en honor de la Unión Soviética; por otro, la mayoría de los arquitectos participantes en la exposición, como Pierre Patout, Marcel Chrétien-Lalanne y otros, entre los cuales se hallaba el bayonés Joseph Hiriart (1888-1946).

\section{FORMACIÓN Y ESTUDIOS}

Joseph Hiriart, hijo de Pierre y de Jeanne Vedet, nació en el número 6 de la calle Pannecau Bayona, el 6 de marzo de 1888. En 1899 ingresó, tras cursar la escuela primaria, en el Seminario de Larresoro, donde recibió una educación clásica basada en la gramática, la retórica, la moral y la literatura. En 1905 se inscribió en la Escuela de Bellas Artes de Burdeos, para estudiar artes industriales y decorativas. Era una escuela pionera, en la cual se formaba los alumnos en la reproducción de modelos neoclásicos por medios industriales; así es como Hiriart, con la ayuda de coleccionistas de arte y empresarios bordeleses, fue formado en todo tipo de técnicas experimentales, tales como la del grabado y la litografía, la reproducción de modelos clásicos, la impresión sobre cerámica, el tapizado o la edición de libros.

Gracias a una beca concedida por el Ayuntamiento de Bayona, pudo inscribirse en la École des beaux-arts de Paris, donde ingresó en 1911 para estudiar arquitectura. Fue admitido en el atelier de Gustave Umdenstock, quien había realizado diversas obras para la Compagnie 
des chemins de fer du Nord. Su informe relativo al primer curso de Hiriart, dice así: «très régulier et assidu, doué au point de vue de son métier; cet élève a de grandes facilités et par dons naturels tous moyens lui permettant de réussir; il a commencé à produire en qualité et en originalité depuis un an» ${ }^{3}$. A tenor de los premios obtenidos durante los cursos posteriores, fue un estudiante ciertamente ejemplar, que obtuvo no pocas medallas y menciones en dibujo, modelado y perspectiva. Imperaba el estilo Beaux Arts, resultado de un siglo y medio de instrucción bajo la autoridad, primero, de la Académie royale d'architecture, y después de la revolución, de la sección de arquitectura de la Académie des Beaux-Arts. Era un estilo clásico, que se nutría de las grandes tradiciones, caracterizado, en lo que a la arquitectura de refiere, por la simetría, la jerarquzación de los espacios, el historicismo, la policromía en sus interiores y un profuso repertorio de elementos ornamentales ${ }^{4}$. Al estilo Beaux-Arts corresponden, por ejemplo, la Opera de Paris, de Charles Garnier, inaugurada en 1875, o la Estación de Orsay, de Victor Laloux, abierta en 1900.

Su carrera quedó interrumpida en 1914, tras estallar la Primera Guerra Mundial (1914-18), toda vez que Francia lo llamó, como al resto de varones menores de 45 años, a luchar por la patria ${ }^{5}$. En el Departamento de los Bajos Pirineos fueron movilizados 45.000 soldados, de los cuales 25.000 salieron de Bayona. Las poblaciones del País Vasco francés quedaron desiertas, paralizándose toda actividad. Hiriart se enroló en la aviación, llegando a ser sargento de la escuadrilla Chauny. El 1 de febrero de 1916, cuando sobrevolaba territorio alemán, su avión fue alcanzado por un tiro, siendo obligado a aterrizar. Fue detenido y trasladado a un campo cercano a Manheim, en el sur de Darmstadt. Había allí 16.000 presos, de los cuales 2.000 eran franceses. Trabajaban a la intemperie, organizados en comandos. El bayonés recurrió a la retórica y a la poesía aprendidas en Larresoro, y gracias a sus dotes escénicas, inventó todo tipo de actividades con el fin de hacer más leve la vida de los demás presos, tales como la publicación de una revista o la programación de funciones de teatro. No obstante, en la primavera de 1917, consiguió escapar del campo y regresar a Bayona ${ }^{6}$. Al tiempo, en reconocimiento a sus actos, recibiría la Cruz de Guerra y la Medalla Extranjera, así como el nombramiento de Caballero de la Legión de Honor.

3 Archives nationales, AJ 52/424, citado en LANNES V.: Joseph Hiriart. Architecte de la lumière. Biarritz atlántica, p. 12

MIDDLETON, R. (Ed.): The Beaux-Arts and Nineteenth-century French Architecture. Londres, Thames and Hudson, 1982

5 BIDEGAIN, E.: Gerla Handia, muga sakona. Lehen Gerla Mundialaren (1914-1918) hastapenak Eskualduna eta Euzkadi aldizkarietan. Donostia, Utriusque Vasconiae, 2009, pp. 1-20.

6 TEXIER S.: Hiriart, Tribout et Beau: architectes. Paris, Université Paris-Sorbonne. UFR Art et archéologie, 1995
Regresó a la vida civil para reemprender sus estudios en 1919, tras ser calurosamente recibido por el director de la Escuela de Bellas Artes de Paris, el retratista bayonés Léon Bonnat. Como muchos otros estudiantes, Hiriart soñaba con recibir el Prix de Rome ${ }^{7}$, premio con el que se reconocía a los estudiantes de mayor talento, consistente en una beca para realizar una estancia de cinco años en la Villa Medici, sede de la Academia Francesa en Roma, situada junto a los jardines de Villa Borghese. Era un premio que además de reconocer los méritos académicos, brindaba la oportunidad de recibir todo tipo de honores y encargos ${ }^{8}$. Dado que tan solo recaía en un estudiante, y a pesar de sus esfuerzos, Hiriart no obtuvo el premio.

Se casó con Joséphine Signoret el mismo año en que reemprendió sus estudios. El padre de Joséphine era de Barcelonnette, Occitania; su madre, Caroline Lacouture, era natural de Ahurti, localidad cercana a Bayona, situada en la ribera del Adur. Los padres de Joséphine se habían conocido en New Biscay, Chihuahua. Su padre, propietario del almacén Palacio del hierro, en Ciudad de Méjico, había prosperado en el mundo de los negocios, y en 1910, la familia regresaba enriquecida al País Vasco. Al poco tiempo, sin embargo, el padre de Joséphine fallecía en un accidente. Joseph y Joséphine se establecieron en París y el bayonés obtuvo su título de Architecte diplômé par le gouvernement en 1922.

\section{EL ESTUDIO DE LA CALLE MARBEUF Y LAS PRIMERAS OBRAS}

En 1922, tan pronto como finalizó sus estudios y gracias a la ayuda de su familia política, Hiriart abrió un estudio de arquitectura en la calle Marbeuf de París, cerca de la avenida de los Campos Elíseos. Se asoció al poco tiempo con Georges Tribout (1890-1970), compañero del atelier de Umbdestock, y con Georges Beau (1892-1958) al cabo de tres años. Era un equipo ambicioso, que no perdería la oportunidad brindada por el concurso de proyectos para un pabellón expositivo convocado por Galeries Lafayette con ocasión de la Exposition internationale des Arts décoratifs et industriels modernes de 1925. Fue precisamente su propuesta la que resultó vencedora. Una propuesta, por cierto, libre de la influencia del Beaux-Arts, el lenguaje académico en el que fueron formados en la Escuela

LANNES V.: op. cit., pp. 14

TRACHTENBERG, M.; HYMAN, I.: Architecture: From Prehistory to Post-Modernism. New York, Harry N. Abrams, 1990, pp. 546-548. 
de Bellas Artes, y al que no recurrirían en ninguna de sus obras posteriores. El pabellón llamado La Maîtrise, adoptaba en planta la forma de un octógono, en cada uno de cuyos vértices se levantaba una columna adornada en su parte superior con una esfinge, diseñada por Léon Leyritz. Por uno de los lados del pabellón, subiendo por una escalinata en piedra, se abría una elegante puerta diseñada por el vidriero Jacques Gruber, con la imagen de un sol resplandeciente (Fig. 1). Al interior, en una serie de estancias y mostradores realizados por los mejores ebanistas y decorados con los más preciosos cueros, vidrios y metales, se exponían los muebles y productos correspondientes al tren de vida de los nuevos tiempos, caracterizado por el lujo y la calidad de los materiales. Fue, ciertamente, uno de los pabellones más célebres de la Exposición’; un icono, cuyas fotografías y crónicas fueron publicadas en cientos de periódicos, libros y revistas, que vendría a colaborar en la difusión de las artes decorativas en toda Europa, en el norte de África o en América ${ }^{10}$.

Gracias al éxito obtenido con La Maitrise, el estudio de la calle Marbeuf se daría a conocer en toda Francia, recibiendo encargos de todas partes, especialmente desde el País Vasco francés. La costa labortana era uno de los lugares donde más claramente se dieron los signos de la nueva era posterior a la guerra, caracterizada por el optimismo, el deseo de divertirse y el lujo, si bien esta vida no estuviera al alcance más que de las clases pudientes. Fue así como floreció sobre la costa vasca una auténtica eclosión arquitectónica, cuyas muestras más llamativas se encuentran en localidades como Saint-Jean-de-Luz, Guéthary, Ciboure o Hendaye. Sirvan como ejemplo la casa en estilo andaluz Barbarenia (1926), en Biarritz, obra de Henri Giraudel, el casino La Pergola en Saint-Jean-de-Luz (1929) de Robert Mallet-Stevens, de estilo moderno, o la villa Bagheera (1926), obra de Pingusson, en Anglet, en la que el arquitecto supo conjugar la arquitectura de Frank Lloyd Wright con toques de la arquitectura española del sur ${ }^{11}$.

9 MOUREY G.: "The Paris International Exhibition 1925: The French Buildings", Studio, 2, 1925, pp 16-19.

10 Para el conocimiento de la exposición de 1925 y de la influencia que esta ejerció en todo el mundo, se recomienda la lectura del catálogo de la exposición conmemorativa organizada en Paris por la Cité de l'architecture et du patrimoine: BRÉON E., RIVOIRARD P. (Dir.s): 1925 Quand l'Art déco séduit monde. Paris, Cité de l'architecture et du patrimoine, 2013.

11 Sirvan, como muestra de la riqueza y pluralidad de estilos que caracterizó a la arquitectura de la época en la costa del País Vasco francés, las siguientes dos rereferencias: BILAS, C.: Les élégantes du Pays basque. Architectures plurielles. 1860-1930. Paris, Les beaux jours, 2012, y NARBAÏTS-FRITSCHI M. Architectes en Pays basque 1920-1930. Bordeaux, Le festin, 2008.

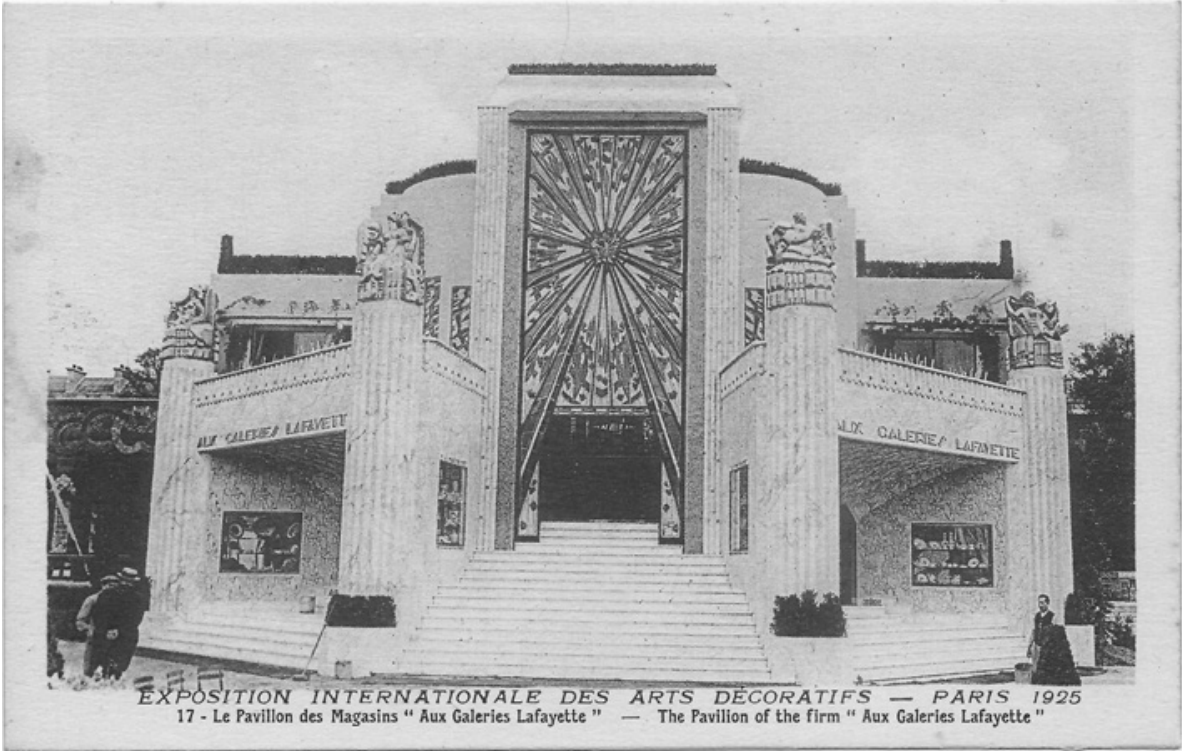

Fig. 1: Pabellón La Maitrise, Galeries Lafayette. Hiriart, Tribout y Beau, 1925. https://commons.wikimedia.org/ wiki/File:Paris-FR-75-Expo_1925_Arts_d\%C3\%A9coratifs-pavillon_des_Galeries_Lafayette.jpg

No obstante, fueron las obras de Joseph Hiriart las que más brillaron en aquella eclosión. Fue requerido en cuanto obtuvo su título para proyectar y dirigir la construcción del Seminario de San Francisco Xavier, en Ustaritz (1924), un gran edificio compuesto por varias alas con salas de estudio, aulas y dormitorios. Una iglesia en su centro y una estatua del santo realizada por Alfred Biberstein formaban el eje de simetría según el cual se ordenaba todo el conjunto. En las escaleras, brillan por su calidad las herrerías de Jean Schwarz y las vidrieras de los hermanos Mauméjean.

Realizó tres villas en la colina de Bordagain, en Ciboure, entre los años 1925 y $1926^{12}$. En la primera de ellas, Lehen Tokia, encargada por un matrimonio inglés, conjugó el estilo vasco con elementos Art-Déco, como la vidriera de Jacques Gruber que muestra a una

12 ALBIZU, D.; VIGIER, F.: Ciboure Architecture. Belles demeures et Lieux historiques de Bordagain 1854 1953. Senpere, Kilika éditions, 2017, pp. 14-18. 
bandada de patos alzando el vuelo. La segunda casa, Itzala, presenta un aspecto más fiel a la arquitectura vasca, no sin que presente algunos elementos ajenos al estilo. En 1926, su suegra le encargó proyectar y construir, junto a la casa Itzala, la que debía ser la casa "más hermosa de la costa vasca, con un patio en su interior, como en las casas que conocimos en Méjico"13. La Señora Lacouture le reclamaba a su yerno un pequeño paráso a salvo del ruido mundanal, en el que pudiera recordar a su marido y a su hijo Jean, muerto en el frente poco antes de que se declarare el armisticio. Hiriart concibió la Villa Leihorra, una imponente casa paladiana de cubierta plana y patio interior, donde los mejores artistas del momento realizaron una serie de aportaciones que merecen ser reseñadas: los mosaicos del ceramista Édouard Cazaux, las herrerías de Jean Schwartz, las vidrieras de Jacques Gruber, los alicatados decorativos de Paul Daum o los muebles de René Prou; al exterior, creó un magnífico jardín en el que resalta la escultura de una cigüeña junto a un niño, realizada en piedra por la escultora flamenca Yvonne Serruys.

Proyectó el Hotel Ghétaria (1926) al borde del mar, y en 1928 recibió el encargo para reconstruir la chappelle du Sacré-Coeur en Hasparren, una capilla en hormigón armado, con planta en cruz. Destacan, por un lado, los frescos pintados por Georges Sauvage, que muestran a una serie de santos y santas, mártires y benefactores admirados por los vascos de la época, y por otro lado, el trabajo de los hermanos Mauméjean, autores de la pintura del Cristo pantocrátor que figura en el ábside, una bóveda de cuarto de esfera iluminada cenitalmente. Fue autor también del Musée de la Mer de Biarritz (1932), un recio y longitudinal edificio situado al pie de los acantilados, en cuya fachada se alza un cuerpo de entrada que remite a la proa de un barco, con marcadas cornisas y vidrios verdes (Fig. 2). Sobre la puerta, luce el bajo relieve de un pulpo, realizado por el escultor de Biarritz Lucien Danglade.

Ciertamente, el equilibrio entre volúmenes y la calidad de los detalles, dan a las obras de Hiriart una factura especial. No obstante, la calidad de estas obras no solo se debe a su talento, o al de sus socios; se debe también a la aportación de algunos de los mejores artesanos de Francia y Bélgica, como los vidrieros Mauméjean y Jacques Gruber, los herreros Jean Schwartz y Gilbert Poillerat, los escultores Alfred Biberstein y Yvonne Serruys, el ceramista Edouard Cazaux o el pintor Georges Sauvage. Todos ellos supieron dar a la obra del bayonés un matiz añadido, ya fuera lúdico, místico o de fascinación por la naturaleza.

13 BILAS, C.: op. cit., p. 66

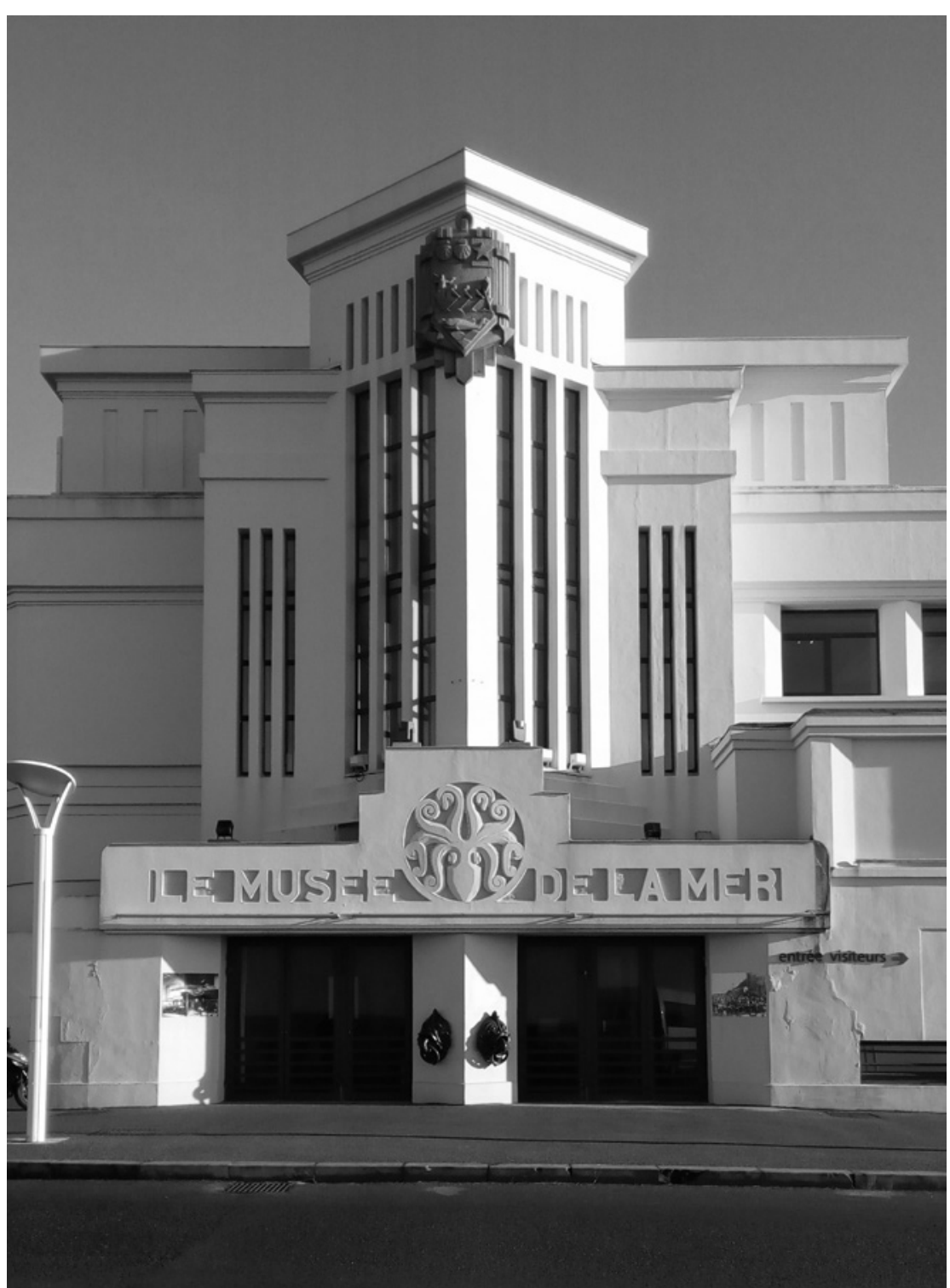

Fig. 2: Cuerpo de entrada del Musée de la Mer. Hiriart, François Lafaye y René Laccourreye, 1932 


\section{A LA BÚSQUEDA DE UN NUEVO MERCADO}

Transcurrida la mitad de la década de 1920, unos años después de la finalización de la Primera Guerra Mundial y tras una etapa de recuperación y de actividad, la economía francesa comenzaría a declinar, y así mismo lo harían los encargos recibidos en el estudio de Hiriart, Beau y Tribout. Ante tal realidad, el bayonés se propuso buscar nuevos mercados en otros países. Las colonias francesas se presentaban como una buena oportunidad; particularmente Túnez, donde el Protectorado llevaba a cabo una política con el fin de atraer a empresas y profesionales franceses. La capital del país experimentaba un crecimiento notable, como consecuencia de la extensión de la ciudad europea y de una serie de nuevos barrios, como Montfleury, Mutuelle-ville, Jeanne d'Arc o Lafayette ${ }^{14}$. No fue con Beau o Tribout con quien emprendió su andadura en Túnez, sino con un nuevo socio, el arquitecto Jean-Marcel Seignouret. Junto con él, abrió un estudio en el número 4 de la calle Bretaña, en el barrio europeo de la capital.

\subsection{Seignouret: un arquitecto francés de Túnez}

Jean-Marcel Seignouret (1898-1963) nació en Auch, capital histórica de Gascuña. Siendo niño, su familia se trasladó a Túnez, donde fue escolarizado en el prestigioso Lycée Carnot. Fue movilizado en la Primera Guerra Mundial, tras finalizar la cual ingresó en la Escuela de Bellas Artes de Paris, pasando, como Hiriart, por el atelier de Gustave Umdenstock Obtuvo su diploma en junio de 1926, distinguiéndose por el dibujo y sus conocimientos de Historia de la Arquitectura ${ }^{15}$.

Cabe mencionar, entre sus primeras obras, el monumento dedicado a los caídos en la guerra de 1914-18, en Fabrézan (Aude), realizado en 1927 junto con el arquitecto Henri Gibert y el escultor Firmin Michelet, así como el proyecto de la École primaire Supérieure de jeunes filles, en Bizerta, en un estilo arabesco, cuyas primeras ideas y trámites comenzaron a mediados de la década de los veinte pero que no fue construido hasta 1931. Continuó con su trayectoria profesional en Túnez tras la Segunda Guerra Mundial, que finalizaría

14 SANTELLI, S.: Tunis. Le creuset méditerranéen. Paris, Éditions du demi-cercle/CNRS éditions, 1995, pp. 59-77.

15 Los datos biográficos relativos a Jean-Marcel Seignouret han sido obtenidos de Aghora. Bases de données de l'Institut national d'histoire de l'art, en la siguiente dirección: https://agorha.inha.fr/inhaprod/ ark:/54721/00284614 (Consultado el 02-04-2020). en 1961, con el proyecto de la École normale supérieure d'institutrices (1961), construido en la capital. Son de subrayar, por otra parte, sus dos iglesias católicas: la iglesia de Beni M’Tir, en el noroeste de Túnez, acabada en 1952 y edificada a solicitud de los ingenieros franceses que dirigían la construcción de una presa en Oued Ellil, y la iglesia de Sers (1953), construida por encargo de los colonos del lugar. Así mismo son de mencionar la ampliación de la escuela de chicos de Bab Saadoun (1955-1967) y la École normale supérieure d'institutrices, en la capital (1961-1974).

\subsection{El estudio de la calle Bretaña, en la ciudad europea}

La ciudad europea de Túnez, concebida como antítesis de la medina árabe, comenzó a construirse con anterioridad a la invasión francesa, al instalarse, junto a las murallas, la oficina de correos de Francia y el consulado de Inglaterra. Fue, no obstante, la construcción de la embajada de Francia (1862) la que daría inicio a su extensión más allá de las inmediaciones de la medina ${ }^{16}$. Su crecimiento adquiriría un empuje ciertamente mayor tras el Tratado del Bardo de 1881, por el por el cual Túnez pasó a estar bajo protectorado francés, afianzándose con la construcción de la catedral católica, construida a partir de 1897, en estilo romano-bizantino ${ }^{17}$. La trama europea nacía en torno a un eje que unía la puerta del mar o Bab al-Bahr, a los pies de la muralla de la medina, con el lago de Túnez. El eje, que adoptó la forma de un boulevard, tomaría el nombre de Promenade de la Marine en su primer tramo (Avenue de Paris tras la proclamación del Protectorado), y el de Avenue Jules Ferry en su tramo más largo y más ancho, hasta su encuentro con el lago. Perpendicularmente a este eje fueron trazadas las avenidas de Cartago y París, una a continuación de la otra; estas últimas, junto con la avenida de Jules Ferry, formaban los ejes principales de la ciudad europea, una suerte de cardo y decumanus del Túnez moderno ${ }^{18}$.

Al final de los años veinte la construcción de la ciudad europea era un hecho imparable: casi todas las parcelas de la Avenida Jules Ferry estaban acabadas, y las Avenidas de Cartago y de París se encontraban en construcción, ya fuera en sustitución de antiguos edificios

16 GIUDICE, C.: "Découverte architecturale et urbanistique du Tunis colonial", en HUEBER, J.; PIATON, C. (Dir. as): Tunis, architectures 1860-1960. Arles-Tunis, Honoré Clair, Elyzad, 2011, pp. 27-40.

17 SANTELLI, S.: op. cit., pp. 74.

18 AMMAR, L.: "Maitres d’ouvre italiens et immeubles de rapport à Tunis, à la fin du XIXème siècle et au début du XXème siècle (1895-1935)", Al-Sabîl: Revue d'Histoire, d'Archéologie et d'Architecture Maghrébines, 2, 2016, pp. 1-13 
o por obras de nueva planta. La gran actividad edificatoria que imperaba en la ciudad era resultado de la importación, desde Europa en general y desde Francia en particular, del fenómeno de la urbanización. Era un proceso inducido por la revolución industrial y favorecido por el desarrollo de infraestructuras, de los medios de transporte, de las nuevas actitudes higienistas y de un arsenal jurídico, cuyas herramientas principales, en lo que a la capital se refiere, consistían en la Ley del Suelo de 1885 y el Reglamento vial de $1889^{19}$. El impulso del Ayuntamiento de Túnez vendría canalizado a través de sus potentes instrumentos de gestión y desarrollo, como la Dirección General de Trabajos Públicos, la Dirección de Obras de la Ciudad, el Servicio Topográfico y el Servicio de carreteras. Estos organismos urbanos llevaron a cabo una remodelación integral, reinventando y modernizando la distribución del espacio extramuros sobre una trama ortogonal y funcionalista ${ }^{20}$.

Sobre dicha trama, a modo de estratos históricos, iría depositándose un rico conjunto de obras, cuyo análisis estilístico da cuenta de la evolución de la ciudad europea: mientras que las casas más antiguas, ubicadas al inicio de la ciudad europea, junto a la puerta Bab al-Bahr y las murallas de la medina, responden al estilo Art Nouveau ${ }^{21}$, las edificaciones que se extienden al este de la ciudad europea responden a los estilos modernos, como el racionalista, el arabesco o el Art-Déco, uno de cuyos máximos exponentes es el conjunto de obras realizas por Hiriart y Seignouret.

De entre sus trabajos finalmente construidos, es preciso subrayar sus bloques residenciales. En primer lugar, fueron, para los dos arquitectos, los primeros proyectos de vivienda colectiva llevados a cabo; el bayonés, autor de magníficas villas y viviendas unifamiliares en la costa vasca, se encontraba por primera vez ante el reto de proyectar inmuebles residenciales de envergadura, situados en las principales calles de la ciudad europea. Es de destacar, en cuanto a la organización interior de los bloques, la querencia que muestran los dos arquitectos por los bloques exentos, es decir no adosados, que brindaban la oportunidad de desarrollar libremente la organización de las viviendas. Gracias a ello,

19 BEN MOUSSA, E.: "Le règlement de voirie de Tunis (1889). Genèse et application", en JELIDI, C. (Dir.a): Villes maghrébines en situations coloniales. Paris-Tunis, Karthala-IRMC, 2014, pp. 182-183.

20 BEN MOUSSA E. "La fabrique du patrimoine en Tunisie, des accommodements coloniaux à l'inflation actuelle", en GMACH, N. ; BEN YOUSSEF, I. ; JEMMALI, S. (Dir.. : Actes de colloque à l'UIK: Patrimoine Matériel et Immatériel, formes et perspectives de développement. Tunis, éditions universitaires de l'UIK, 2016, pp. 86-119.

21 BACHA, M.: "L'Art nouveau à Tunis", Les annales de l'Équipement, 7, 1997, pp. 41-56.

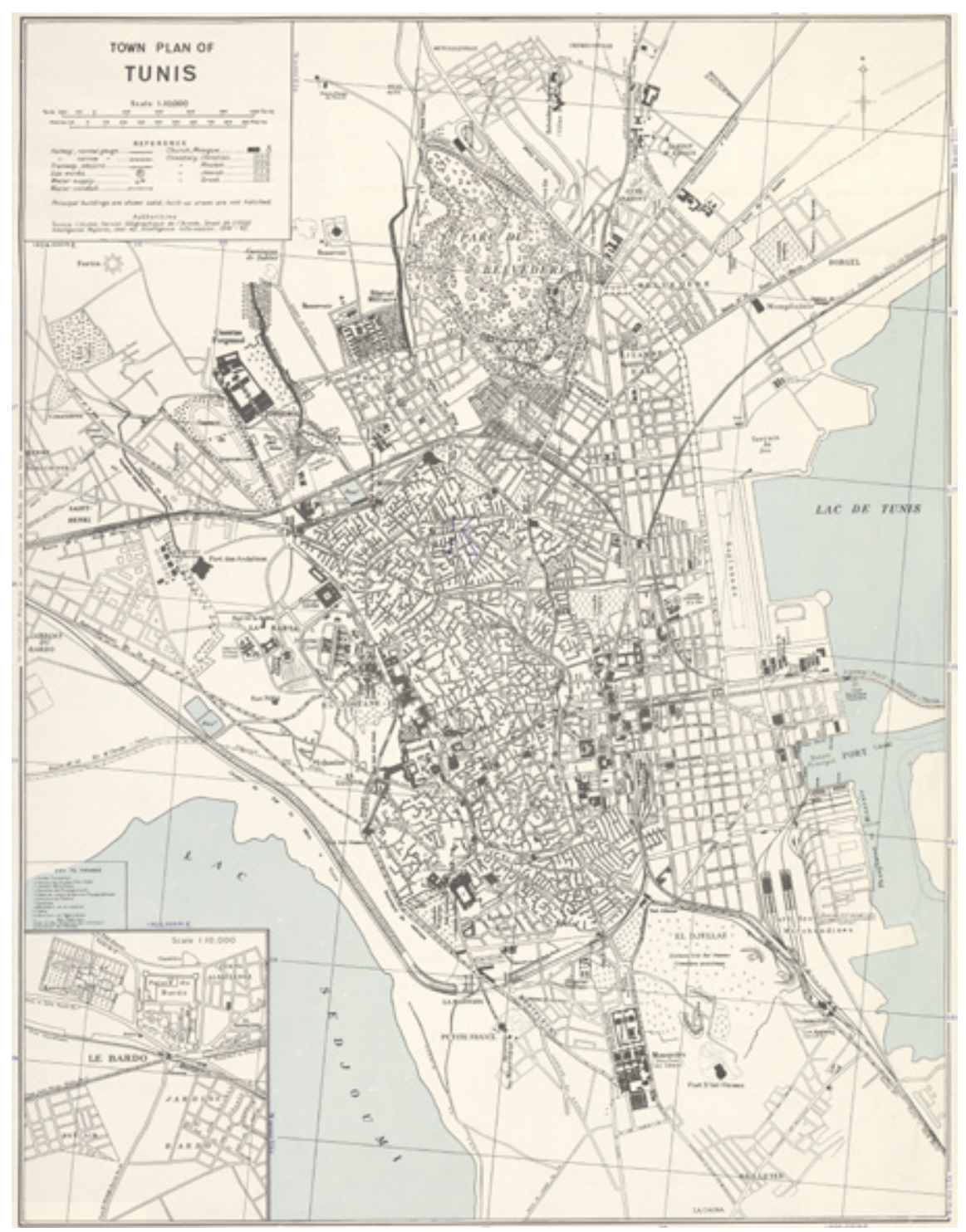

Fig. 3: Plano de la ciudad de Túnez. 1942. https://commons.wikimedia.org/wiki/File:Tunis_1942_US_Army_ Map.jpg 
garantizaban la correcta ventilación e iluminación de las estancias, facilitando, además una simetría central de las plantas tipo, en benficio del orden, del equilibro entre las partes y de la economía estructural.

Por otra parte, en lo que a la composición y aspecto de las fachadas se refiere. Hiriart y Seignouret recurrieron al estilo Art-Déco; eso sí, fruto de su propia interpretación: en él destacan los elementos volumétricos realizados en hormigón armado, como antepechos volados, columnas exentas por el exterior de la fachada, pilastras rematadas por capiteles o bajorrelieves. Gracias a ello, sus fachadas adquieren un movimiento que llama la atención en el conjunto de la ciudad europea, y un juego de luces y sombras que varía en función de la evolución del soleamiento. Además, diseñaron cuidadosamente los trabajos de herrería ya fueran celosías, rejas o barandillas, realizados por artesanos italianos, que combinarían con trabajos de vidriería de composición abstracta o gemétrica en la mayoría de los casos. Supieron así mismo integrar elementos árabes, como arcos en herradura, o símbolos pertenecientes al imaginario masónico.

En contraposición a estos rasgos que dan un carácter especial a sus trabajos, es de destaca la ausencia, en las fachadas de sus edificios, de elementos ornamentales realizados en pintura, comunes en la arquitectura Art-Déco, así como del empleo de otros metales al margen de la forja, o de otras técnicas basadas en la adhesión de piezas cerámicas, como los azulejos y los mosaicos, comunes, por otra parte, en los edificios realizados por los arquitectos italianos de la misma época; sievan como ejemplos el bloque de viviendas de $\mathrm{n}^{\circ} 1$ de la calle Abou-Dulama (1937), de Vito Silvia, o en el inmueble Gastone, en la calle Farhat-Hached (1937), de Remo Radicioni ${ }^{22}$

22 HUEBER J., PIATON C.: Tunis, architectures 1860-1960. Arles-Tunis, Honoré Clair, Elyzad, 2011, pp $143-191$

\section{OBRAS TUNECINAS DE JOSEPH HIRIART}

\subsection{La propuesta para la estación de ferrocarril (1929)}

En 1877, la Compagnie des chemins de fer Bône-Guelma, propietaria de la red de ferrocarril de Argelia, se hacía con la concesión de la línea de ferrocarril desde Túnez hasta la ciudad de Souk-el Arba. Con ella llegó la construcción de la estación de Francia en 1877, en el límite de la Petite Sicile, un conjunto de manzanas al sur de la Avenue Jules Ferry y al este de la Avenida de Cartago, habitado por la colonia italiana. La primera estación consistía en un pequeño edificio, frente al cual se abría la Place de la gare du sud, con edificios de corte clasicista o en estilo Art Nouveau.

A pesar de que el interior del país fuera montañoso, los franceses se empeñaron a fondo en extender una red de ferrocarril, con el propósito, no solo de garantizar el transporte de viajeros y el suministro, sino también el de enlazar todo el país con el puerto de Bizerta desde donde partirían los barcos con todo tipo de materias extraídas de las plantaciones y minas $^{23}$. A finales de 1929, la Dirección General de Obras Publicas convocaba un concurso de anteproyectos para una nueva estación de ferrocarril, en sustitución de la anterior. E tribunal declaró desierto el primer premio ${ }^{24}$. El segundo, de 20.000 francos, fue a manos del arquitecto parisino Lévêque; era un edificio de tres plantas en cuyo centro se levantaba el cuerpo de acceso, con una torre y un reloj. Fue el proyecto elegido, no sin incorporar una serie de correcciones a propuesta del jurado. Hiriart y Seignouret obtuvieron el sexto premio por su edificio de aspecto industrial e influencia constructivista, enfatizado con una esbelta torre ${ }^{25}$. Según la revista Chantiers $^{26}$, el proyecto era fruto de un concienzudo estudio de la organización interior, de manera que los viajeros abonados podían entrar directamente a las vías, sin necesidad de entrar por el gran hall de las taquillas.

23 MANSOUR, M. "Genèse d'une gare, genèse d'une ville. Cas du quartier de la gare des voyageurs de Tunis", Al-Sabîl: Revue d'Histoire, d'Archéologie et d'Architecture Maghrébines, 5, 2018, pp. 1-17.

24 QUATTROCCHI, L. L'architettura coloniale in Tunisia. Dall'orientalismo all’Art Déco, 1881-1942, Milano-Torino, Pearson Italia, 2013, p. 79.

Pechit. $65-75$

26 La nouvelle gare de Tunis (Abril de 1930). Chantiers. Revue mensuelle illustrée de la construction en Afrique du Nord, pp. 325-334. 


\subsection{El monumento a Paul Bourde, en Sfax (1929)}

El monumento en homenaje a Paul Bourde consiste en un monumento situado en la ciudad de Sfax, al borde del Golfo de Gabés, a casi $300 \mathrm{~km}$ de la capital. Apenas se había instalado en Túnez, Hiriart recibió el encargo para realizar el monolito en homenaje al agrónomo Paul Bourde, un aventurero con una especial querencia por Túnez, que exigió al gobierno francés la aplicación de mejoras y de nuevos sistemas de plantación e irrigación, con el fin de hacer más fértiles las secas tierras del sur. Una vez nombrado director de Agricultura, puso en marcha un programa de ayudas para recuperar, en colaboración con los colonos del lugar, técnicas de irrigación empleadas por los romanos en la antigüedad, favoreciendo así el desarrollo y garantizando el abastecimiento de aceite de oliva a la metrópoli.

En 1927 las autoridades del gobierno colonial impulsaron la construcción de un monumento en honor de Bourde, fallecido 10 años antes. Decidieron levantarlo en el barrio de BabBhar, en la céntrica plaza del barrio europeo de la ciudad de Sfax. Al igual que en la capital, una nueva ciudad de rectas calles fue adosada a la medina por su lado $\operatorname{sur}^{27}$. El monumento, compuesto de un monolito y de un busto, quedaría situado en el centro de un jardín ${ }^{28}$, rodeado por una cadena de hierro y ornamentos en forma de huevo (Fig. 4). Hiriart proyectó en estilo Art-Déco una mole de planta octogonal con molduras geométricas y una cúpula nervada. Por su cara este se le adosó el busto realizado por Yvonne Serruys (18731953), la autora, recordemos, de la escultura de la cigüeña y el niño que luce la fachada oeste de Villa Leihorra. El monumento fue inaugurado el 13 de abril de 1930.

\subsection{El inmueble de la avenida Jules Ferry (1930)}

El primer inmueble que Hiriart y Seignouret levantaron en Túnez se sitúa en la Avenida Jules Ferry, principal arteria de la capital. Fue promovido por Simon Zana, con el fin de alojar en él apartamentos de alquiler. El inmueble ocupa una parcela rectangular en la esquina con la calle Bretaña, por lo que cuenta con dos fachadas. Las ordenanzas urbanísticas impidieron que este primer bloque fuera exento. El proyecto fue desarrollado durante el año 1930, y la construcción, en hormigón armado, se llevó a cabo entre los años 1930 y 1932, bajo la dirección del contratista Raphaël Bono ${ }^{29}$.

27 ATTARD, C.; BACQUET, G.: Sfax: 1881-1956. Tunis, Sud Éditions, 2005.

28 MONNOYER, C.: "Nouvelles et correspondances", Revue de botanique appliquée et d'agriculture coloniale, 7, 1927, pp. 510-511

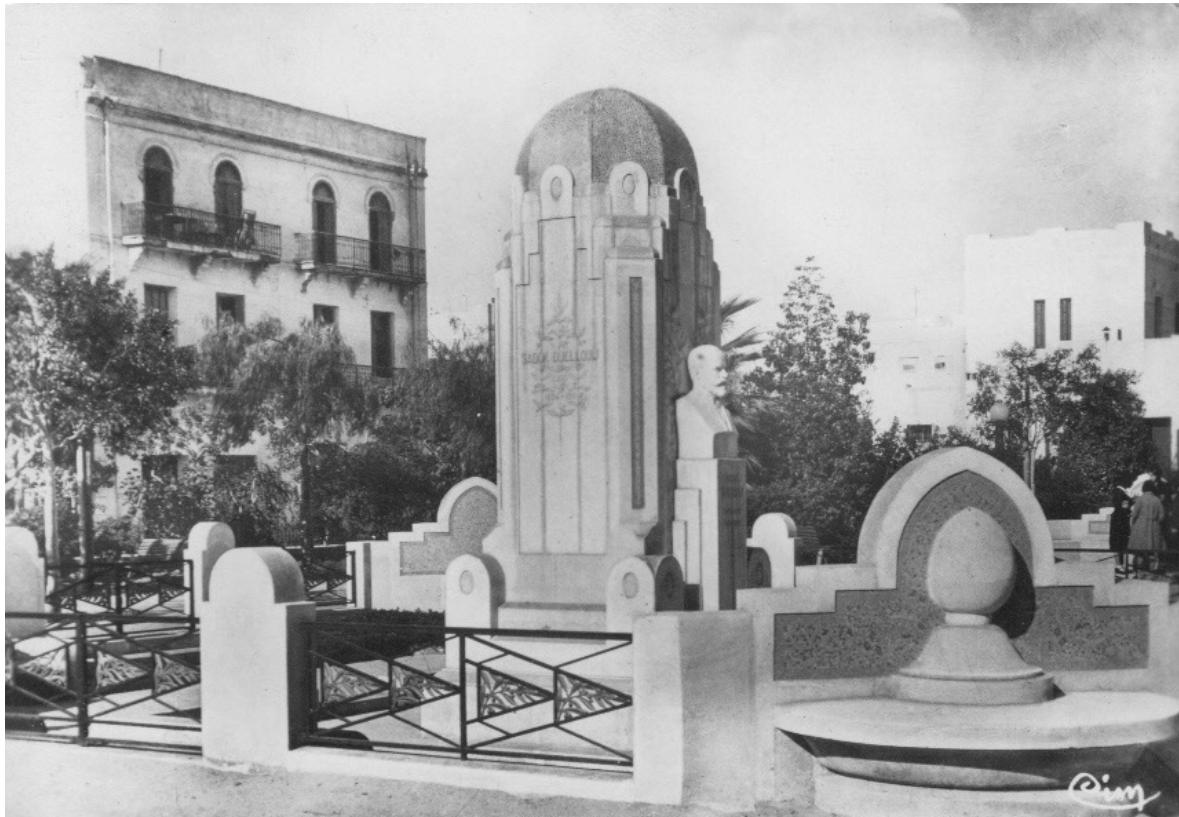

Fig. 4: Monumento a Paul Bourde en Sfax. Hiriart y Serruys, 1929. https://commons.wikimedia.org/wiki/File:Statue_de_Paul_Bourde_\%C3\%A0_Sfax.jpg

La planta baja quedó destinada a locales comerciales, mientras que las plantas altas se ocuparían con tres apartamentos de dos dormitorios y un apartamento de tres, cada uno de los cuales cuenta con salón, comedor, un vestíbulo, cocina, cuarto de baño y trastero. La planta última difiere por el lado de la calle Bretaña, ya que como consecuencia de las ordenanzas municipales, y con el objeto de no oscurecer en exceso la calle, hubo que retrasar la alineación, dando espacio a una terraza con pérgola. La cubierta consiste en una terraza transitable, que, como era habitual en Túnez, fue destinada a los servicios de limpieza y

29 Archives de la municipalité de Tunis. Immeuble sur la propriété de Monsieur Simon Zana. Avenue Jules Ferry. Architectes: Hiriart et Seignouret (1931). Registre de Voirie, 12094. 
lavandería de los apartamentos, con sus cuartos particulares para hacer la colada, y un espacio para tender la ropa, al que se accede desde la caja de escaleras. Dado que la casa se encontraba adosada a otros bloques por su lado este y sur, los arquitectos abrieron un patio principal de unos $25 \mathrm{~m}^{2}$ con el fin de ventilar e iluminar las estancias, además de otros tres patios menores de $8 \mathrm{~m}^{2}$ de superficie para la ventilación de las escaleras, cocinas y cuartos de baño.

Dada su ubicación a pie de la principal de las avenidas de la capital, Hiriart y Seignouret diseñaron cuidadosamente los detalles de la fachada principal, acentuando el juego entre líneas horizontales y verticales, y dando al inmueble un carácter moderno, a la vez que monumental. Así es como las fachadas presentan una serie de elementos historicistas, que a su vez se integran en un juego de volúmenes de corte racionalista. La parte central de la fachada a la avenida Jules Ferry, dispuesta en vuelo, está embellecida por esbeltas pilastras de capitel jónico. Todo el cuerpo central descansa sobre unas gruesas ménsulas molduradas, que marcan la separación con la planta baja. La parte superior de la fachada está rematada por un friso que acentúa el carácter simétrico de la fachada (Fig. 5). Lo balcones, resueltos con delgadas losas en hormigón armado, están protegidos por barandas de delgadas pletinas de hierro y dibujos ornamentales. Es de subrayar, por otra parte, la elegancia de la puerta en hierro forjado, obra del maestro italiano M. Farrugia ${ }^{30}$. La composición de la fachada sur, la racionalidad del plano y la diversidad de materiales utilizados, hacen que el edificio adopte un carácter racionalista, no sin ser matizado por los elementos ornamentales propios del Art Déco.

5.4. El bloque de apartamentos de la Compagnie des Assurances générales (1934)

Hiriart y Seignouret obtuvieron el primer premio en el concurso para construir la sede de la Compagnie des Assurances Générales, garantizándose el encargo del proyecto, que arrancó en 1934 y se desarrolló durante el año $1935^{31}$. La construcción del edificio fue encargada en su totalidad a los empresarios M.M Casaluce y Ali Tapka. Además de su programa principal, cuyo fin era el de servir como sede de la compañía, el proyecto incorporaba una serie de locales comerciales en planta baja, así como un número de apartamentos en sus plantas altas, con todas las mayores comodidades de la época.

30 Un nouvel immueble (Architectes MM. Hiriart et Seignouret) (marzo de 1932). Chantiers. Revue mensuelle illustrée de la construction en Afrique du Nord, p. 227

31 Archives de la municipalité de Tunis. Registre de Voirie, 3815 (8 de diciembre de 1933).

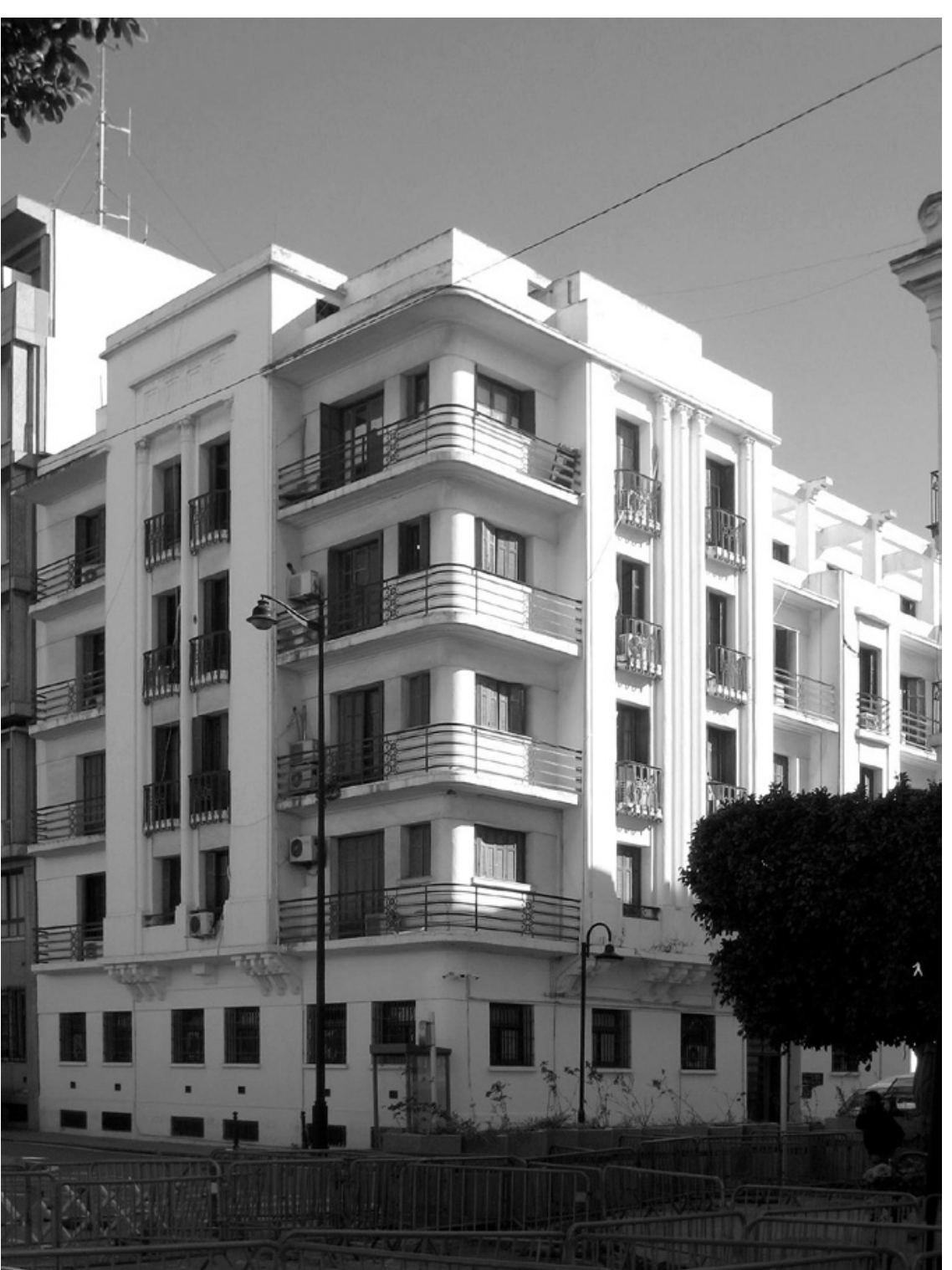

g. 5: Inmueble de la avenida Jules Ferry. Hiriart y Seignouret, 1930 
A diferencia del inmueble de la avenida Jules Ferry, se trataba de un bloque exento. La parcela, de forma rectangular, alcanzaba una superficie de unos 850 metros cuadrados, $y$ se situaba entre la calle Constantine, la calle Souk Ahras y la calle Bône (actualmente calles Mohamed Ali y calle Annaba). El edificio fue construido con una estructura enteramente realizada en hormigón armado, incluidas las fachadas. Fue levantada por la Société Métropolitaine Fourrée et Rhodes, y sus forjados fueron dotados con un sistema novedoso de aislamiento acústico, mediante intercalación de capas independientes de hormigón y corcho ${ }^{32}$. El cálculo y diseño de la estructura fue llevado a cabo por los ingenieros Georges Demarre y Harry Novak, de la conocida sociedad Hennebique ${ }^{33}$, que propusieron la construcción de los muros de sótano mediante dobles muros de hormigón con una lámina impermeable intercalada ${ }^{34}$.

La entrada al edificio, desde la rue Bône, da acceso a un gran patio interior de unos 50 metros cuadrados, del que arrancan las dos escaleras principales dispuestas a ambos lados del patio, con sus correspondientes ascensores. Una escalera secundaria se eleva tan solo hasta la primera planta, dando acceso a las oficinas de la compañía: una serie de locales de diversos tamaños dispuestas a lo largo de largos pasillos, iluminados por grandes ventanales orientados al patio.

Las tres plantas residenciales están ocupadas por diez apartamentos de una o dos habitaciones, con cocina, cuarto de baño y aseo. Los cuartos de servicio fueron dispuestos en torno al gran patio central, mientras que las salas de estar y los dormitorios quedaron orientados a la calle (Fig. 6). En la cuarta planta, el plano se modifica y la distribución de los apartamentos cambia, dando lugar a apartamentos de menor tamaño. A pesar de la complejidad del programa, la concepción del edificio responde a una absoluta racionalidad ${ }^{35}$.

32 L'immeuble des Assurances générales (10 de enero de 1935). Journal des travaux publics et du bâtiment: organe du Syndicat des entrepreneurs de travaux publics de l'Algérie et de la Tunisie, p. 5.

33 La empresa Hennebique contaba con una competitiva red compuesta de técnicos y comerciales en todo el mundo; también en el Magreb, con más de una docena de oficinas y concesionarios establecidos en Argelia, Marruecos y Túnez, con sus delineantes e ingenieros. Lease la siguiente referencia en relación a la empresa Hennebique: DELHUMEAU, G.: L'invention du Béton Armé. Hennebique. 1890-1914. Paris, Norma, 1999.

34 Archives de la municipalité de Tunis. Immeuble rue de Constantine rue de Bone et Rue Souk-Ahras. Compagnie d'Assurances Générales. Architectes: Hiriart et Seignouret (1933). Registre de Voirie, H-8045. 35 HUEBER J., PIATON C.: Tunis, architectures 1860-1960. Arles-Tunis, Honoré Clair, Elyzad, 2011, p. 150

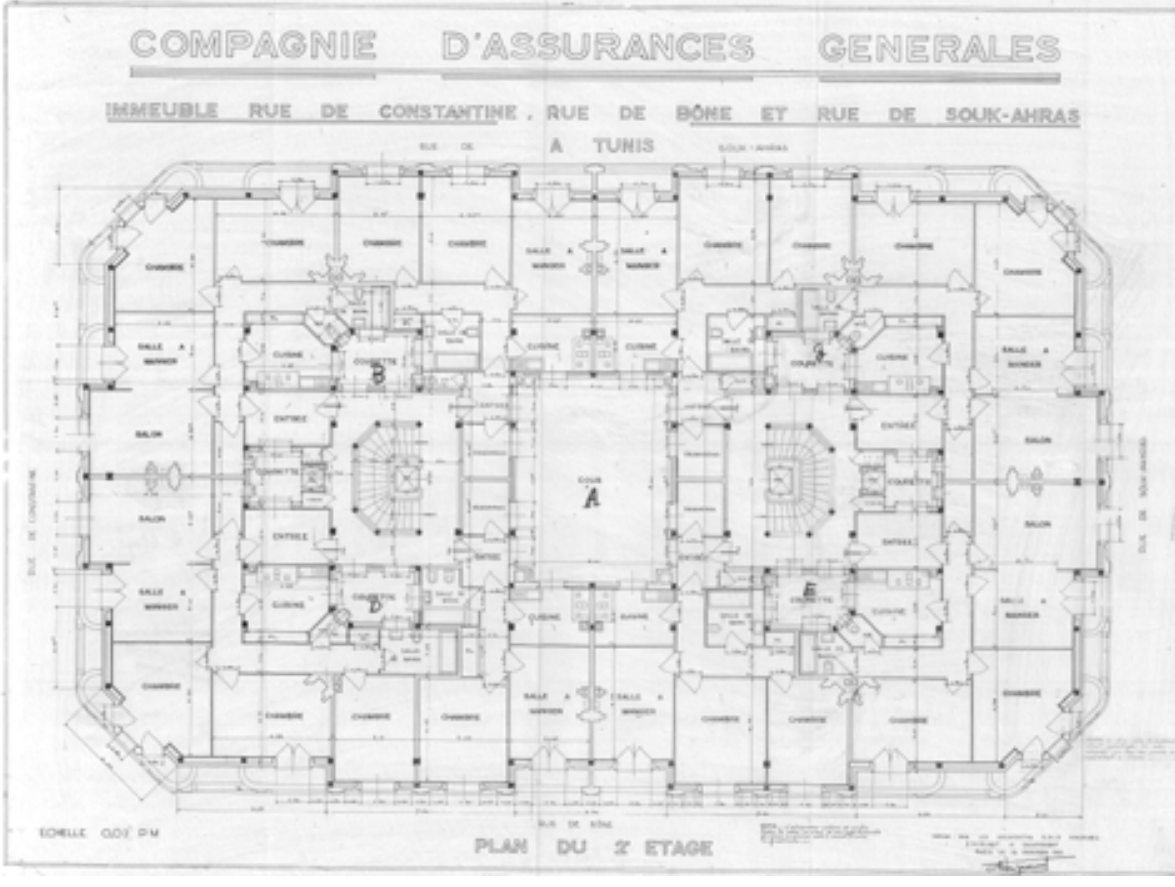

Fig. 6: Planta segunda del bloque de apartamentos de la Compagnie des Assurances générales. Hiriart y Seignouret, 1934. Archivo Municipal de Túne’

La lectura de las fachadas denota voluntad de estratificar su composición. En primer lugar, los arquitectos dispusieron de una enfática losa volada como elemento de separación entre la planta baja y las plantas altas. En las fachadas laterales, por otra parte, sobre un volumen rectangular que vuela de la alineación de la fachada, los arquitectos abrieron hileras de ventanas rectas en las plantas primera y segunda, mientras que en la tercera, recurrieron a elementos que remiten a la arquitectura árabe, como las ventanas en arco de herradura encuadradas en un alfiz. También recurrieron a elementos árabes en la puerta de acceso a la casa: una puerta en hierro forjado, adornada por una greca de motivos geométricos que imita a un alfiz. Cuatro estrechas ventanas de medio punto situadas sobre el alfiz confieren un aire arabesco al acceso principal de la casa; bajo él, una doble inscripción, en árabe y en francés, da cuenta del promotor y del año de construcción. No obstante, dada la estrechez 
de las calles que lo rodean, los arquitectos trataron de ubicar en las esquinas los elementos más expresivos de la fachada: en la primera planta, destinada a oficinas de la compañía ubicaron un balcón corrido que recibe el cuerpo volado y los miradores poligonales; en la segunda planta, el balcón de antepecho curvo se limita a la esquina, y en la tercera, el mirador da paso a una logia (Fig. 7).

\subsection{La ampliación del Lycée Carnot (1935)}

El Lycée Carnot (actualmente Lycée Pilote Habib Bourguiba) constituye el símbolo de la educación francesa en Túnez, así como el de la integración de las élites del país ${ }^{36}$. Su primer centro, levantado en Cartago por el Cardenal Lavigerie en 1875, fue trasladado a Túnez en 1882, y adoptado por la administración del Protectorado en 1889, bajo el nombre inicial de Lycée Sadiki. Con la entrada en el siglo veinte y con la nueva denominación de Lycée Carnot, el establecimiento educativo comenzó a ser objeto de diversas intervenciones proyectadas por Victor Valensi, el arquitecto tunecino que proyectó la Gran Sinagoga de Túnez (1912) y que trató de conjugar el Movimiento Moderno con la arquitectura tradicional del Magreb ${ }^{37}$.

Las salas y aulas levantadas durante la Belle Époque habían quedado obsoletas en los años veinte $^{38}$, por lo que en 1931 los responsables encargaron el proyecto para un nuevo centro a Valensi. Es así como se levantó toda una nueva ala con una fachada monumental hacia la calle Habib-Thameur; una fachada de más de cien metros de largo, con una portada central y dos secundarias a ambos lados, compuesta por una acentuada cornisa con triglifos y una serie regular de amplias ventanas con un refinado trabajo de herrería.

No obstante, al poco tiempo de finalizarse la obra de Valensi, el colegio requeriría la construcción de una sala de fiestas. El proyecto recayó, por mediación del propio Valensi, en Joseph Hiriart ${ }^{39}$. Se trataba de un encargo comprometido desde el punto de vista

36 HUEBER J., PIATON C.: op. cit., p. 150.

37 DEMERDASH-FATEMI, N. "L'Habitation tunisienne de Victor Valensi (1928). Visions d'un architecte de culture juive sur le pluralisme des modernités vernaculaires en Tunisie", Perspective, 2, 2017, pp. $189-200$

38 LANNES V.: op. cit., p. 127

Archives Nationales de Tunisie. Plans correspondances et notes concernant l'agrandissement de Lycée 39 Carnot à Tunis. Architectes: Hiriart et Seignouret (1941-56). FPC M3 0015-0396.

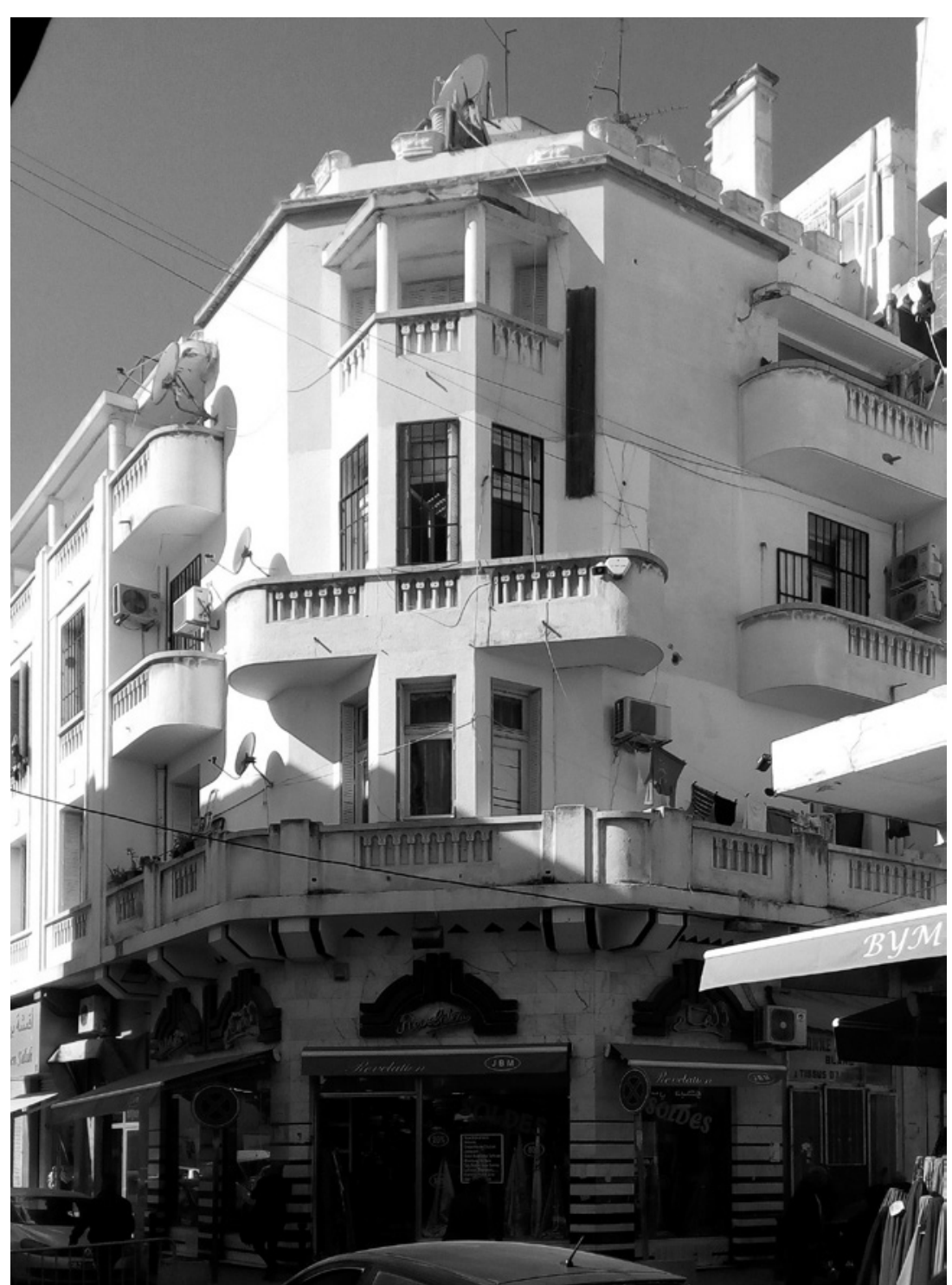

7: Esquina del bloque de apartamentos de la Compagnie des Assurances générales. Hiriart y Seignouret, 1934 
arquitectónico, ya que la sala iba a adosarse al recio edificio levantado poco tiempo antes. Hiriart y Seignouret proyectaron una monumental puerta de acceso a la sala de actos, valiéndose de la flexibilidad del estilo Art Déco, que podía nutrirse por igual de elementos de raíces africanas o de carácter racionalista. Fue tal la ambición con la que acometieron el encargo que la nueva puerta terminaría haciendo sombra, por siempre, a la larga fachada de Valensi.

Hiriart compuso un blanco y robusto cuerpo paralelepipédico en hormigón, en cuyo seno se abría una puerta de proporciones similares a las de La Maîtrise o la Villa Leihorra enmarcada entre dos columnas papiriformes de tamaño colosal (Fig. 8). A un tercio de la altura de la puerta, dispuso un balcón curvo con una balaustrada, y bajo ella, la puerta de acceso con un rico trabajo de vidriería y herrería entrelazada. El borde de la puerta está adornado con dos filas de puntas de diamante, y sobre ella, luce un llamativo friso en forma de bajorrelieve, con dibujos geométricos que pertenecen al imaginario masónico ${ }^{40}$ : las columnas del templo de Salomón en los extremos; en el centro, las herramientas: la sierra de dientes las escuadras y la cuerda con nudos; y repartidos entre todos los elementos, los tres puntos simbólicos ${ }^{41}$.

La puerta es una obra de gran elegancia: la utilización de motivos egipcios, el recurso al imaginario masónico y los elegantes trabajos de herrería hacen de ella un elemento único, de gran carácter, que anuncia el carácter de templo del saber que le corresponde a un liceo. La elegancia de la puerta, no obstante, se extiende al interior del vestíbulo, en una suerte de continuidad estilística: después del gran foyer, se eleva a la derecha una magnifica escalera de dos tramos en piedra, con una balaustrada en hierro forjado y un sinuoso pasamanos hecho en madera. En el entresuelo, a la altura del balcón exterior, una vidriera espectacular con motivos geométricos inunda de luz el interior. El interior de la sala presenta una estructura de balcones en hemiciclo, según un riguroso trazado geométrico, con asientos tapizados en tonos cálidos.

40 ARIZA, F.: La Masonería. Símbolos y ritos. Zaragoza, Libros del Innombrable, 2007

41 HUEBER J., PIATON C.: op. cit., p. 143

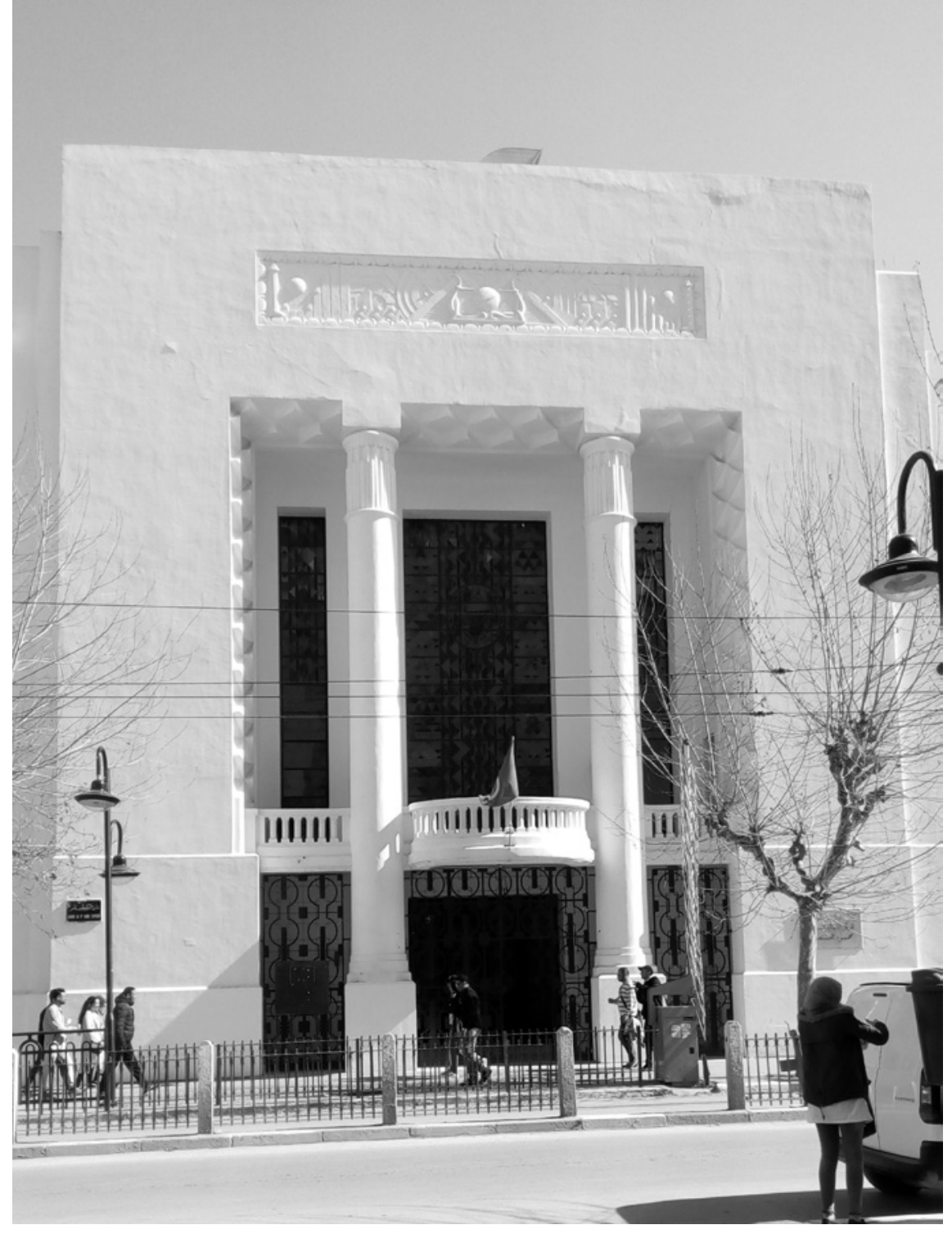

Fig. 8: Puerta de acceso a la sala de actos del Lycée Carnot. Hiriart y Seignouret, 1935 


\subsection{El bloque de Schwich et Baizeau en la avenida de Cartago (1936)}

El ingeniero Vincent Schwich comenzó su carrera en Argelia, instalándose después en Túnez en 1890 para representar los intereses de la sociedad Pavin-Lafarge. En 1902, se asoció a Lucien Baizeau, para comercializar materiales de construcción, creando la empresa Schwich et Baizeau, la cual garantizaría el suministro que la colonización agrícola requería para su instalación en todo el territorio ${ }^{42}$.

Baizeau conocía y apreciaba la arquitectura moderna. Recurrió a Le Corbusier pocos años antes para que proyectara su villa en Cartago (1928). Era consciente de la importancia de la arquitectura en el ámbito de las finanzas y la empresa, incluso como medio de representación y posicionamiento social. Así, seducidos por el interés que en aquella época presentaba la céntrica avenida de Cartago, los asociados tuvieron la idea de edificar allí la monumental nueva sede de su empresa. Tras la adquisición de la parcela y la demolición de los dos pequeños edificios preexistentes, la empresa convocó un concurso de arquitectura, que ganaron Hiriart y Seignouret.

Con la edificación de la sede social de los establecimientos Schwich et Baizeau, en el ángulo entre la avenida de Cartago y la calle Portugal, los dos asociados deseaban demostrar el poderío de la empresa y la evolución experimentada por ella ${ }^{43}$. Fue, de hecho, una de las mayores operaciones inmobiliarias realizadas en el periodo de entreguerras en la ciudad de Túnez. Mediante su edificación, que comenzó en 1936, los dos socios deseaban materializar y hacer ver la fulgurante e innegable ascensión de la empresa.

Es un edificio de siete pisos; su planta, cuya superficie alcanza los 3.300 metros cuadrados, tiene una anchura de 38 metros y una longitud de 57 (Fig. 9). No es fácil organizar distribuir una superficie de tal tamaño; menos aún si, en lugar de amplios espacios de uso colectivo, se trata de albergar viviendas, con sus estancias y servicios auxiliares, tales como patios, escaleras y accesos. En cualquier caso, Hiriart y Seignouret resolvieron con éxito la distribución de la planta tipo, de tal manera que cada una de sus partes responde al cometido que le corresponde, integrándose coherentemente en el conjunto de usos y espacios.

42 HUEBER J., PIATON C.: op. cit., pp. 152-153.

43 BILAS, C.: Tunis, lorient de la modernité. Paris, éditions de l'Éclat, 2010, pp. 214-215.
Los dos vestíbulos de acceso están situados en las fachadas laterales: uno en la calle Portugal (hoy en día Farhat Hached) y otro en la calle Marceschau (Oum-Kalthoum). Ambos dan paso a unas amplias cajas de escaleras cuyo diseño demuestra el cuidado que los arquitectos dedicaron a los detalles. En cuanto a los paramentos, Hiriart y Seignouret recurrieron a los tonos blancos y grises, que enfatizaban la claridad geométrica y recordaban a los interiores típicos en Paris, evitando los colores vivos, desmesuradamente empleados en las promociones tunecinas llevadas a cabo por los constructores italianos.

$\mathrm{Al}$ igual que en el bloque de Assurances Générales, los arquitectos insertaron en el centro del edificio un patio de unos 80 metros cuadrados de superficie (Fig. 10). Además de este patio principal, incorporaron otros cuatro patios menores cuya forma resultaba de la macla de dos cuadrados al bies. La organización de la planta tipo es absolutamente simétrica: a cada lado, sirviendo cada una de ellas a dos viviendas por rellano, ubicaron tres cajas de escaleras cuidadosamente diseñadas y con amplios ventanales a los patios. En cada planta se integran doce viviendas de dos o tres dormitorios, cuarto de baño y aseo, cocina, sala de estar y comedor. Son viviendas de amplia superficie, cuyos servicios se agrupan en torno a los patios menores ${ }^{44}$.

Es de subrayar el cuidado con el que los arquitectos estudiaron y resolvieron la circulación de los residentes y la del servicio; a cada lado de la planta tipo incorporaron una cuarta escalera, independiente del resto de escaleras, para la entrada y salida del servicio, el suministro, las compras y la basura. La coherencia entre la estructura porticada y la distribución interior del edificio es, por otra parte, absoluta.

En la azotea fue dispuesta una terraza en torno al patio central, y en ella, junto a las cajas de escaleras y ascensores, los cuartos de aseo y colada para el servicio y los empleados de las oficinas. A la altura del entresuelo, un recio voladizo envuelve ininterrumpidamente el edificio. La fachada situada por debajo de él, a la altura de la calle y entre los huecos de los locales comerciales, fue pintada en tonos terrosos; por encima del vuelo, sin embargo, es blanca, y se compone de tres elementos: una serie de balcones con pilastras adosadas, ventanas rectas y las logias de las últimas plantas. Mediante la combinación de estos elementos, y gracias a la incorporación de unos falsos balcones, los arquitectos compusieron una vívida fachada que confería cierta levedad a un edificio de semejante robustez.

44 Archives de la municipalité de Tunis. Immeuble à Tunis. Schwich et Baizeu. Architectes: Hiriart et Seignouret (1936). Registre de Voirie, 13726 


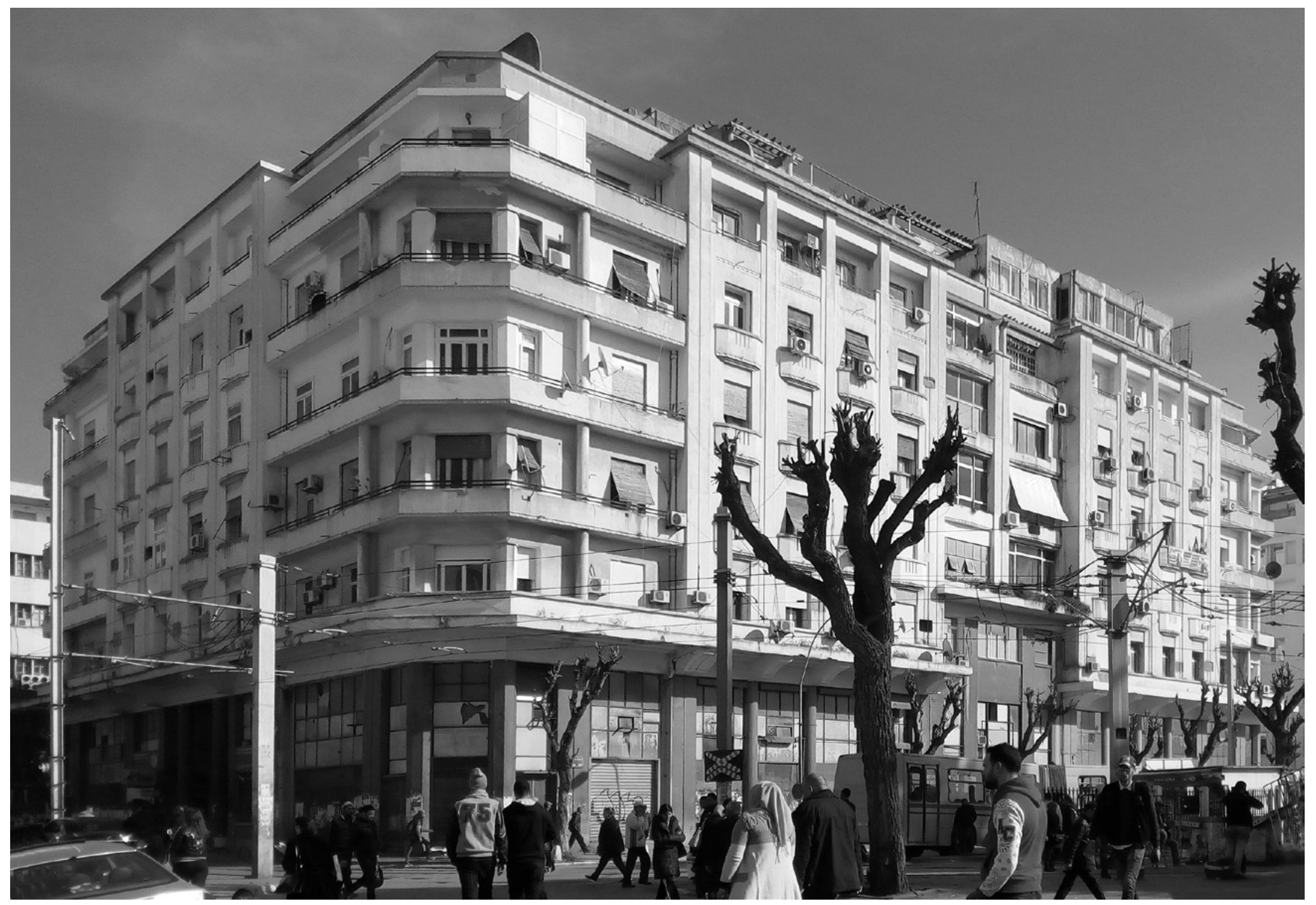

Iig. 9: Vista del bloque Schwich et Baizeau en la avenida Cartago. Hiriart y Seignouret, 1936 


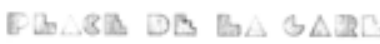

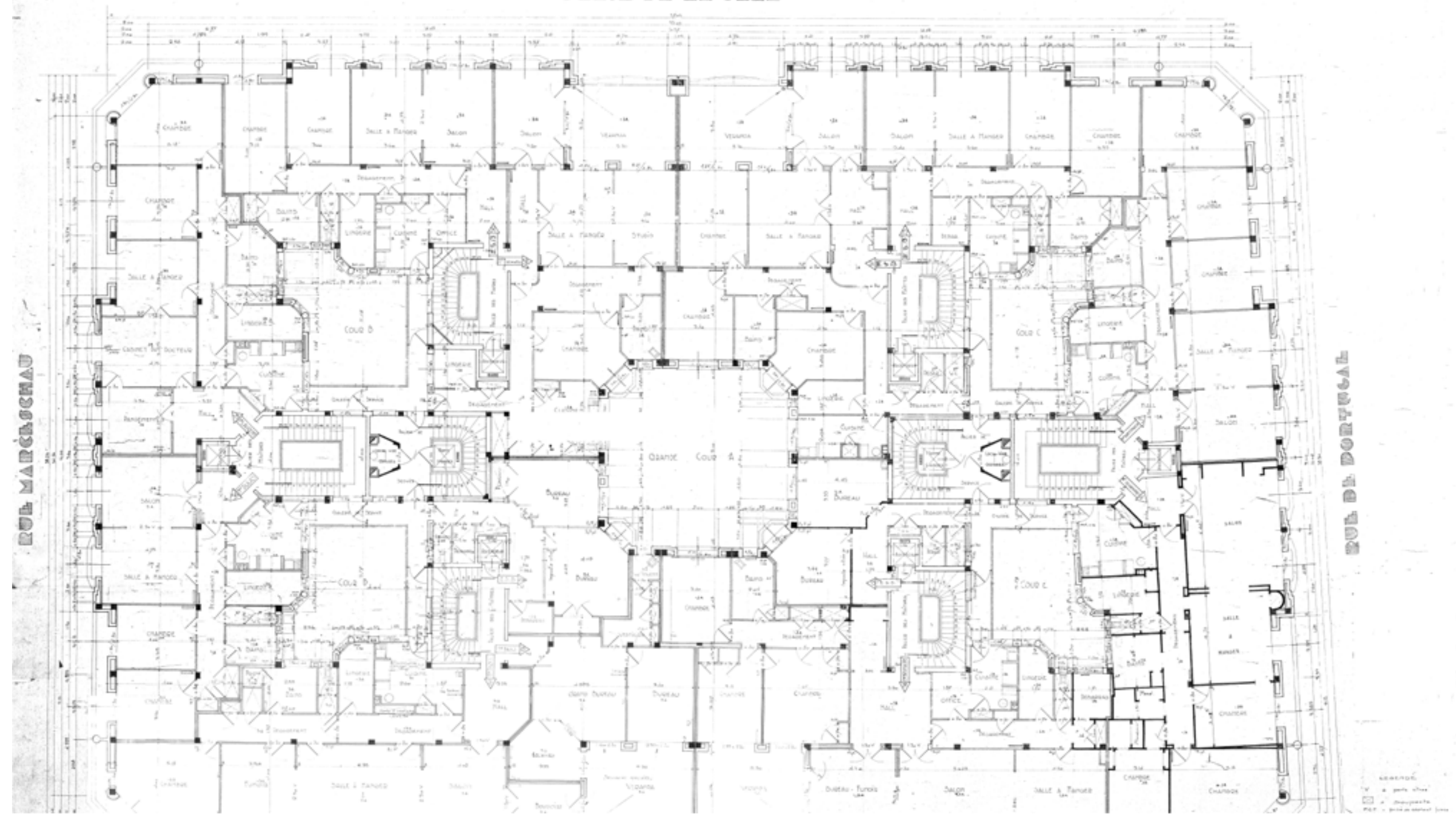

Fig. 10: Planta tipo del bloque Schwich et Baizeau en la avenida Cartago. Hiriart y Seignouret, 1936. Archivo Municipal de Túnez 


\section{FIN DE LA ETAPA TUNECINA}

Con el bloque de Schwich et Baizeau finalizaba la etapa profesional de Hiriart en Túnez. Fue una etapa que duró cerca de diez años, si bien es cierto que sus visitas al país eran esporádicas y alternadas con sus estancias en París y sus viajes al País Vasco. No obstante, gracias a la calidad de sus obras y a su relación con Seignouret y Valensi, Hiriart logró integrarse y darse a conocer en la comunidad francesa, asegurándose la continuidad de los encargos. Al margen del proyecto para la estación de ferrocarril (1929), supo atraer la atención y obtener encargos como el monumento a Paul Bourde (1929), la ampliación del Lycée Carnot (1935) y sus tres bloques residenciales: el inmueble de la Avenida Jules Ferry (1930), los apartamentos de la Compagnie des Assurances Générales (1934) y el gran bloque de Schwich et Baizeau (1936) forman la totalidad de la obra de Hiriart en Túnez.

El bayonés fue uno de los principales representantes de la arquitectura Art-Déco, con una carrera jalonada de obras brillantes, la mayoría de las cuales fueron llevadas a cabo en el País Vasco. No obstante, Hiriart representa también a uno de los lenguajes arquitectónicos de los que el colonialismo se valió durante el periodo de entreguerras para edificar e impulsar la extensión de sus ciudades de ultramar. Gracias a la invasión, ocupación y colonización de los países del Mahgreb, se abría, a finales del siglo XIX, un vasto mercado para los arquitectos franceses formados en la École des beaux-arts de Paris. Es el caso de Hiriart, quien, perfectamente integrado en la comunidad francesa de Túnez y auspiciado por el Protectorado, desarrolló, entre 1927 y 1936, la etapa profesional descrita en este artículo.

¿Por qué terminó la etapa tunecina? Fue sin duda la crisis de los años 30 lo que impulsó a Hiriart a abandonar Túnez, cuya situación comenzó a empeorar en 1934. Hasta entonces, el Protectorado había puesto a disposición de los colonos miles de hectáreas de tierra fértil, facilitando técnicas y maquinaria moderna para trabajar el campo, y disponiendo de créditos para la construcción de granjas, así como un amplio mercado donde vender sus productos. Sin embargo, a partir de 1934, como consecuencia de la caída de la cotización del trigo, el aceite y el vino, los colonos agricultores se vieron incapaces de pagar sus deudas y préstamos, por lo que muchas explotaciones fueron a la quiebra. Con cientos de familias endeudadas, el Protectorado entero entró en una dura crisis ${ }^{45}$. Era una época de gran conflictividad, latente, aunque no sólo en Túnez; en Francia, el caso Stavisky provocó la

45 PONCET, J.: "La Crise des années 30 et ses répercussions sur la colonisation française en Tunisie", Revu française d'histoire doutre-mer, 1976, Vol. 232-233, pp. 622-627. indignación de la oposición francesa, y en 1934, los grupos de la oposición y los antiguos combatientes, entre los cuales se encontraba el bayonés, llamaban a concentrarse ante el Parlamento de Francia ${ }^{46}$.

Terminada la etapa tunecina, Hiriart regresaba al estudio de la calle Marbeuf, donde ejercería durante diez años más. Participó en 1937 en la Exposition internationale des Arts et des Techniques dans la Vie moderne, en París, donde proyectó, junto con Tribout Beau, el pabellón de Lorraine y el pabellón del Aluminio. Tras la Segunda Guerra Mundial, segunda guerra también para Hiriart, fue encargado de dirigir la reconstrucción de la ciudad de Sisterón, en el límite norte de la región de Provenza, tarea a la que no pudo dedicar más que un año. Falleció el 17 de noviembre de 1946, en París, a la edad de 58 años.

\footnotetext{
46 LANNES V.: op. cit., pp. 22-25.
} 


\section{BIBLIOGRAFÍA}

ALBIZU, D.; VIGIER, F.: Ciboure Architecture. Belles demeures et Lieux historiques de Bordagain 1854-1953. Senpere, Kilika éditions, 2017.

AMMAR, L.: "Maîtres d’œuvre italiens et immeubles de rapport à Tunis, à la fin du XIXème siècle et au début du XXème siècle (1895-1935)", Al-Sabîl: Revue d'Histoire, d'Archéologie et d'Architecture Maghrébines, 2, 2016, pp. 1-13. https://www.al-sabil.tn/?p=2364 (Consultado el 2/04/2020).

ARIZA, F.: La Masonería. Símbolos y ritos. Zaragoza, Libros del Innombrable, 2007.

ATTARD, C.; BACQUET, G.: Sfax: 1881-1956. Tunis, Sud Éditions, 2005.

BACHA, M.: "L’Art nouveau à Tunis", Les annales de l'Équipement, vol. 7, 1997, pp. 41-56.

BEN MOUSSA, E.: "Le règlement de voirie de Tunis (1889). Genèse et application", en JELIDI, C. (Dir. $\left.{ }^{a}\right)$ : Villes maghrébines en situations coloniales. Paris-Tunis, Karthala-IRMC, 2014, pp. 182-183.

BEN MOUSSA E.: "La fabrique du patrimoine en Tunisie, des accommodements coloniaux à l'inflation actuelle", en GMACH, N. ; BEN YOUSSEF, I. ; JEMMALI, S. (Dir.s : Actes de colloque à l'UIK: Patrimoine Matériel et Immatériel, formes et perspectives de développement. Tunis, éditions universitaires de l'UIK, 2016, pp. 86-119.

BIDEGAIN, E.: Gerla Handia, muga sakona. Lehen Gerla Mundialaren (1914-1918 hastapenak Eskualduna eta Euzkadi aldizkarietan. Donostia, Utriusque Vasconiae, 2009.

BILAS, C., Tunis, l'orient de la modernité. Paris, éditions de l'Éclat, 2010.

BILAS, C.: Les élégantes du Pays basque. Architectures plurielles. 1860-1930. Paris, Les beaux jours, 2012.

BRÉON E., RIVOIRARD P. (Dir.s): 1925 Quand l’Art déco séduit le monde. Paris, Cité de l'architecture et du patrimoine, 2013.
DelHumeaU, G.: L'invention du Béton Armé. Hennebique. 1890-1914. Paris, Norma 1999.

DEMERDASH-FATEMI, N.: “L'Habitation tunisienne de Victor Valensi (1928). Visions d'un architecte de culture juive sur le pluralisme des modernités vernaculaires en Tunisie", Perspective, 2, 2017, pp. 189-200. https://journals.openedition.org/perspective/7662 (Consultado el 03/04/2020).

ETXEPARE, L.: “Joseph Hiriart: hiru arkitektura-lan Tunisen 1930-1936”, Aldiri, 38, 2019 pp. 20-24.

GIUDICE, C.: "Découverte architecturale et urbanistique du Tunis colonial”, en Hueber, J. Piaton, C. (Dir. ${ }^{\text {as }}$ ): Tunis, architectures 1860-1960. Arles-Tunis, Honoré Clair, Elyzad, 2011, pp. 27-40.

HUEBER J., PIATON C.: Tunis, architectures 1860-1960. Arles-Tunis, Honoré Clair, Elyzad, 2011.

JELIDI, C. (Dir. $\left.{ }^{a}\right)$ : Villes maghrébines en situations coloniales. Paris-Tunis, Karthala-IRMC, 2014.

LANNES V.: Joseph Hiriart. Architecte de la lumière. Biarritz, atlantica, 2015.

MANSOUR, M.: "Genèse d'une gare, genèse d'une ville. Cas du quartier de la gare des voyageurs de Tunis", Al-Sabîl: Revue d'Histoire, d'Archéologie et d'Architecture Maghrébines, 5, 2018, pp. 1-17. http://www.al-sabil.tn/?p=4412 (Consultado el 2/04/2020).

MIDDLETON, R. (Ed.): The Beaux-Arts and Nineteenth-century French Architecture. Londres, Thames and Hudson, 1982

MONNOYER, C.: "Nouvelles et correspondances", Revue de botanique appliquée et d'agriculture coloniale, 7, 1927, pp. 510-511.

MOUREY G.: "The Paris International Exhibition 1925: The French Buildings”, Studio, 2, 1925, pp. 16-19. 
NARBAÏTS-FRITSCHI M.: Architectes en Pays basque 1920-1930. Bordeaux, Le festin, 2008.

PONCET, J.: "La Crise des années 30 et ses répercussions sur la colonisation française en Tunisie”, Revue française d'histoire d'outre-mer, 1976, 232-233, pp. 622-627. https://www. persee.fr/doc/outre_0300-9513_1976_num_63_232_1962 (Consultado el 05/04/2020).

QUATTROCCHI, L.: Larchitettura coloniale in Tunisia. Dallorientalismo all'Art Déco, 1881-1942. Milano-Torino, Pearson Italia, 2013.

SANTELLI, S., Tunis. Le creuset méditerranéen. Paris, Éditions du demi-cercle/CNRS éditions, 1995.

TEXIER S.: Hiriart, Tribout et Beau: architectes. Paris, Université Paris-Sorbonne, UFR Art et archéologie, 1995.

TRACHTENBERG, M.; HYMAN, I.: Architecture: From Prehistory to Post-Modernism. New York, Harry N. Abrams, 1990. 